Article

\title{
Risk Perceptions and Flood Insurance: Insights from Homeowners on the Georgia Coast
}

\author{
Craig Landry * and Dylan Turner (D) \\ Department of Agricultural and Applied Economics (AAEC), University of Georgia, Athens, GA 30602, USA; \\ dylan.turner25@uga.edu \\ * Correspondence: clandry@uga.edu
}

Received: 26 September 2020; Accepted: 4 December 2020; Published: 11 December 2020

\begin{abstract}
Scholars highlight a wide array of factors that can influence individual decision-making under risk. Utilizing survey data, we explore many potential factors that affect risk perception and protective behaviors. Our focus is on coastal Georgia, which has lower historical risk relative to the rest of the Southeast U.S., and which many people perceive as relatively safe, but was recently adversely affected by two major storms. The results indicate a majority of coastal residents expect coastal storms and other hazards to be worse in the future. The regression results suggest perceived damages, risk tolerance, wealth exposure, and flood zone are robust determinants of flood insurance purchase. Other factors, like flood zone awareness and attitudes towards community risk management initiatives-like shoreline armoring, beach replenishment, and coastal retreat—are also indicated to have a high correlation with flood insurance purchase.
\end{abstract}

Keywords: flood risk; risk perceptions; risk preference; insurance

\section{Introduction}

Understanding how to adapt to and limit the impacts from natural catastrophes is an increasingly pertinent issue, as costs associated with U.S. natural catastrophes have been increasing for several decades [1]. This is due to the increased global frequency of catastrophic events [2-4], but is also partially a result of increased exposure from urbanization and development in hazard-prone areas, particularly in the U.S. [5]. Of naturally occurring catastrophes, tropical cyclones and associated flooding are by far the most costly [1]. Consequently, the U.S. government has been heavily involved in actively mitigating and managing flood impacts. Starting in the early 20th century, the U.S. began trying to limit the impacts from flooding by building flood control infrastructure, which has expanded into a network of over $28,000 \mathrm{~m}$ of levees as well as numerous sea walls, dams, and canals [6]. Measures have been taken to limit fiscal impacts as well. The National Flood Insurance Program (NFIP) was created in 1968 with the stated goal of reducing losses from flooding and limiting public spending for disaster aid.

Despite these well-intentioned efforts to limit the physical and pecuniary impacts from natural catastrophes, the effectiveness of government efforts is often undermined by individuals' actions that, in many cases, ultimately define the extent of damages and associated costs. For example, mandatory flood insurance requirements are often circumvented [7]. Individuals have also been shown to forgo insurance when expectations of government ex-post disaster aid are high [8] and to reduce insurance coverage in response to distribution of aid [9-11]. These are some of the contributing factors that explain why only 30 percent of U.S. homeowners in 100-year flood zones have flood insurance [12]. This statistic is 
counter-intuitive given that the NFIP offers rates that are not risk-based [13], meaning that many policies have positive expected values over the life of a standard 30-year mortgage, and decision predictions of rational choice models suggest that households should opt for full coverage [14].

While there has been a surge of interest in flood risk governance, particularly in the European Union [15], issues of efficiency and legitimacy complicate flood resilience in the U.S. Federal flood protection, insurance, and mitigation initiatives are primarily designed as "top-down" programs that take little account of spatial heterogeneity [16,17], are unevenly applied at the local level [18], and provide for feedback effects that largely reflect pre-existing political power [19]. Misinformation and individual misperceptions can also be problematic. For example, areas protected by levees are not considered flood zones, despite significant residual risk being present. In such instances, individuals may or may not be aware of such risks, especially if they rely on flood zone classifications as a proxy for risk information. Along this same line, flood zone maps are often imprecisely drawn or outdated, leaving many individuals with misleading information on the risks they are exposed to. Anecdotally, in the case of Hurricane Harvey, 75 percent of flood losses occurred outside the SFHA, where flood risks were thought to be negligible [20]. More generally, Federal Emergency Management Agency (FEMA) flood maps indicate that 13 million U.S. households face a one percent annual risk of flooding, while estimates from other researchers put that number at closer to 41 million U.S. households [21].

Government efforts to mitigate impacts from natural hazards are less likely to be effective if the goals of individuals and government are poorly aligned, or if individuals have inaccurate perceptions and unfounded expectations. Consequently, understanding which individual beliefs and expectations influence individual decisions relevant to natural hazard mitigation is critical for promoting widespread systemic resilience against future natural catastrophes. This is not a trivial task. For instance, the combination of low probabilities and high consequences that natural hazards exhibit creates an ideal environment for behavioral biases to manifest; this is but one the many challenges faced in trying to understand individual decisions [22]. Additionally, public perceptions and expectations are dynamic and evolve over time, particularly with issues related to climate change [23], meaning that existing studies can become outdated quickly.

The aim of this study is to provide insight into the current state of attitudes, expectations, preferences, and perceptions of coastal residents pertaining to low-probability, high-consequence natural hazards. In particular, we explore how these factors correlate with flood insurance holdings (at both the extensive (who buys?) and intensive (how much coverage do people take?) margins). Using a novel data set collected via mail survey in the fall of 2018 in coastal Georgia (USA), we highlight some of the most important factors to consider for designing policy that aligns the interests of individuals with the goal of systemic adaptation to reduce negative impacts from future catastrophes.

Our results are unique in several regards. Many studies focusing on the relationship between individual perceptions of risk and natural hazard mitigation tend to focus on perceptions of present risks [24-27]. For natural hazards that are likely to worsen in the future as a result of climate change (tropical cyclones, sea level rise, coastal flooding), however, beliefs about the future may be a better indicator for natural hazard mitigation decisions. Understanding how individuals update their beliefs about future coastal risks and whether or not those beliefs about the future are reflected in hazard mitigation decisions appears to be under-explored in the existing literature. In addition, many recent studies investigating individual attitudes, opinions, perceptions, or expectations related to natural hazard mitigation or climate change adaptation have been based on samples collected from outside the U.S. [24,27]. It is not obvious that results from these studies generalize to the institutional setting of the U.S. (due to differences in tropical cyclone risk, development patterns, flood insurance markets, and other institutional and cultural factors). 
In addition, existing studies in the U.S. utilizing survey data tend to draw samples from areas that have extensive historical exposure to natural catastrophes (such as the Gulf Coast $[28,29]$ ), areas that have recently experienced a major natural hazard (such as New York City following Hurricane Sandy [25]), or recruit subjects specifically in flood zones [26]. On the contrary, the Georgia coast exhibits a relatively lower hurricane return period than most other areas of the Southeast [30,31]; due to shallow offshore bathymetry and the concave shape of the coastline, the Georgia coast, in general, is seen as a "safe haven" from tropical storms, but this is based only on recent historical data [32] and does not take storm surge risk into account [33]. Nonetheless, coastal Georgia was recently affected by two significant storms (Matthew in 2016 and Irma in 2017); this situation provides an opportunity to assess how populations with perceived low risk may respond to new information. More generally, climate change is likely to broaden exposure of natural hazards for much of the world's population in a similar manner; such populations may be particularly vulnerable to behavioral biases and heuristics that may be ineffective at promoting efficient self-protection behaviors.

Although Glynn County has had lower historical flood exposure compared to other parts of the southeastern United States, it still exhibits higher flood risk exposure compared to the broader coastal U.S. regions [34]. Additionally, the Southeast and Mid-Atlantic coasts of the U.S. are projected to witness an increase in the share of high-flood-risk properties over the next 30 years (relative to the rest of the country) [35]. The coast of the southeastern U.S. is unique in that it is one of the few highly populated regions in the world that is routinely hit by tropical cyclones. Southeast Asia is the only other region in the world that experiences tropical cyclones at similar frequencies [36]. This is notable since many of the major flood events that hit the southeastern U.S. are accompanied by wind hazards, which can compound flood damage. Coastal Georgia and the broader southeastern U.S. are projected to experience climate-change-induced increases in flood risk exposure that are on par with Central and Latin America, much of South America, parts of Sub-Saharan Africa, northern Australia, and much of Northeast Asia [37]. Southeast Asia and the Philippines, along with select parts of Sub-Saharan Africa, are the only regions with projected flood exposure increases greater than the southeastern U.S. On the other hand, other parts of the U.S., Canada, and most of Europe and Western Asia are expected to witness lower flood risk exposure in the future.

Overall, utilizing coastal Georgia as a research site provides data on a population that is likely to have lower previous perceptions of risk relative to nearby coastal areas, despite being in a relatively high-risk region when compared to the broader U.S. and the rest of the world. Our paper is organized as follows. Section 2 reviews our data collection and survey procedures. Section 3 presents and explores descriptive statistics for our data. Section 4 describes our empirical methodology, with Section 5 reporting results. Section 6 discusses our findings, while Section 7 concludes.

\section{Data}

Our data set consists of household-level information that was collected via a mail survey in the fall of 2018. Recent home buyers (transactions in 2016 or 2017) in Glynn County, GA were targeted, and 1914 surveys were sent out in early October, of which 266 were returned (for a response rate of $13.9 \%$ ). Incentive payments of 5 USD were offered for returned surveys. The survey instrument was designed to capture information on homeowner attitudes, expectations, beliefs, and behaviors related to living and investing on the coast, within the broader context of climate change. Our data set notably includes both flood and wind insurance information, elicited expectations of the likelihood of hurricanes over the next 50 years, expected damages from a hurricane, degree of worry across multiple domains, and elicited risk preferences.

Likelihood of a Category 3 hurricane and expected damage were elicited using subjective assessment instruments. Probability of a major hurricane was measured by asking respondents to estimate the number 
of Category 3 storms or greater to strike their community in the next 50 years; we used these data to approximate an annual probability of hurricane strike. To assess expected damages, we asked respondents to indicate the level of damage that they thought would result from a Category 3 storm as a percentage of structural home value.

To elicit risk preferences, survey respondents had the option to wager their incentive payment as part of a risk preference instrument based on [38]; the risk preference instrument allowed respondents to select from among multiple risky lotteries with varying levels of risk and payoffs (all relative to keeping the incentive payment). The natural uncertainty associated with future weather outcomes was used to generate the randomness in payoffs. Each lottery was based on future weather outcomes at a particular weather station in Glynn County, GA, with payoffs being tied to occurrence of particular weather outcomes. For example, the safest gamble (associated with minor risk aversion), was a 50/50 gamble on rainfall being less than, equal to, or greater than the historical average, with associated payoffs of 8 or 3 USD, respectively; the riskiest gamble (associated with risk loving) was a $2.5 \%$ chance of 300 USD if a the high temperature reached a particular level (0 USD payment if not).

Historical information on rainfall and temperature was relayed to respondents to provide a common basis for objective assessment. As individuals may have subjective assessments of weather that deviate from historical data, we also asked them whether they think particular outcomes are more or less likely than indicated by historical data. This design has the benefit of framing risk in a common and relevant domain (weather outcomes), and it removes any doubt about the randomness of the outcome, since the payoffs are based on data that researchers cannot manipulate and respondents can independently verify.

\section{Descriptive Statistics}

Table A1 lists variable descriptions for each variable in our data, while Table 1 reports descriptive statistics. What follows is a description of the various elements used in our analysis. 
Table 1. Descriptive statistics.

\begin{tabular}{|c|c|c|c|c|c|}
\hline & Mean & sd & $\min$ & $\max$ & Count \\
\hline \multicolumn{6}{|l|}{$\underline{\text { Panel A: Insurance }}$} \\
\hline$\overline{\text { Flood Policy }}$ & 0.62 & 0.49 & 0.00 & 1.00 & 266 \\
\hline Flood Premium (Calculated) & 1314.94 & 1294.34 & 152.57 & 6036.70 & 266 \\
\hline Primary Home & 0.48 & 0.50 & 0.00 & 1.00 & 266 \\
\hline SFHA & 0.26 & 0.44 & 0.00 & 1.00 & 266 \\
\hline Knew Zone & 0.70 & 0.46 & 0.00 & 1.00 & 266 \\
\hline Wealth Share & 0.33 & 0.22 & 0.10 & 0.90 & 261 \\
\hline $\mathrm{Km}$ to coast & 4.47 & 2.86 & 0.33 & 13.09 & 266 \\
\hline \multicolumn{6}{|l|}{ Panel B: Demographics } \\
\hline$\overline{\text { Female }}$ & 0.30 & 0.46 & 0.00 & 1.00 & 266 \\
\hline White & 0.88 & 0.33 & 0.00 & 1.00 & 266 \\
\hline Age & 55.12 & 14.49 & 21.00 & 80.00 & 258 \\
\hline Higher Edu. & 0.67 & 0.47 & 0.00 & 1.00 & 266 \\
\hline Income & 171.67 & 149.36 & 30.00 & 496.12 & 253 \\
\hline Conservative & 0.49 & 0.50 & 0.00 & 1.00 & 266 \\
\hline Retired & 0.26 & 0.44 & 0.00 & 1.00 & 266 \\
\hline Household Size & 2.45 & 1.17 & 1.00 & 6.00 & 257 \\
\hline New to Coast & 0.41 & 0.49 & 0.00 & 1.00 & 266 \\
\hline Life Time Resident & 0.10 & 0.30 & 0.00 & 1.00 & 266 \\
\hline Coastal Vet. & 0.35 & 0.48 & 0.00 & 1.00 & 266 \\
\hline Flood Damage & $31,800.00$ & $59,725.99$ & 300.00 & $300,000.00$ & 37 \\
\hline Prior Flood & 0.15 & 0.36 & 0.00 & 1.00 & 261 \\
\hline \multicolumn{6}{|c|}{ Panel C: Expectations and Perceptions } \\
\hline Worse Erosion & 0.77 & 0.42 & 0.00 & 1.00 & 266 \\
\hline Worse Storms & 0.61 & 0.49 & 0.00 & 1.00 & 266 \\
\hline Armoring & 0.54 & 0.50 & 0.00 & 1.00 & 266 \\
\hline Retreat & 0.58 & 0.49 & 0.00 & 1.00 & 266 \\
\hline Exp. Disaster Aid (Individual) & 0.35 & 0.48 & 0.00 & 1.00 & 266 \\
\hline Exp. Disaster Aid (Public) & 0.58 & 0.50 & 0.00 & 1.00 & 266 \\
\hline Exp. Disaster Aid (Loans) & 0.51 & 0.50 & 0.00 & 1.00 & 266 \\
\hline Prob Hurricane & 0.19 & 0.24 & 0.00 & 1.00 & 238 \\
\hline Expected Damage & 0.43 & 0.23 & 0.10 & 0.90 & 254 \\
\hline CRRA & 0.49 & 0.38 & 0.01 & 0.85 & 251 \\
\hline Worry (Home Loss) & 0.46 & 0.50 & 0.00 & 1.00 & 266 \\
\hline Observations & 266 & & & & \\
\hline
\end{tabular}

\subsection{Insurance}

Current flood insurance policies were held by $62 \%$ of households in our sample, with a mean annual flood premium of 1313 USD. We calculated the flood insurance premium each homeowner would face for full coverage on their home's structure, assuming a 1000 deductible USD, using the NFIP flood insurance rate manual [39]. This calculated premium had a mean value of 1314 USD. Actual premiums may vary based on deductible choice and choice of full versus partial coverage, but the calculated premium is tailored to the home's flood zone and characteristics, as dictated by the NFIP manual. Thus, the calculated premium provided for a consistent (and more plausibly exogenous) metric of price for both policy holders and non-policy holders to be used for analysis of flood insurance demand.

About half of the respondents indicated that their Glynn County home was their primary residence. Flood zone status was elicited from survey respondents, but also verified using flood zone maps. Twenty-six percent of homes in the sample were located in a special flood hazard area (SFHA-zone 
with a $1 \%$ flood risk per annum). Seventy percent of the respondents correctly identified their flood zone. Substantial heterogeneity in flood risk awareness, however, existed across flood zones. Only 39\% of residents with homes in SFHAs correctly indicated as such, compared to $80 \%$ of residents with homes in non-SFHA zones. This is possibly indicative of respondents having a tendency to indicate not being in a flood zone if they do not know they are in a flood zone. Additionally, a smaller proportion of homes in SFHA zones were indicated to be primary residences (28\%) compared to non-SFHA homes (54\%), which may explain the discrepancy in flood zone awareness, as non-permanent residents may be less cognizant of or less concerned with local flood risks. The average respondent indicated that $33 \%$ of their wealth was represented by coastal property ownership. The average home in our sample was determined to be about $4.5 \mathrm{~km}$ from the coast.

\subsection{Demographics}

The minority of survey respondents (30\%) were female; $88 \%$ of our sample was white, and the average age was 55. Sixty-seven percent had completed a bachelor's degree or graduate degree. Annual household income was elicited in a series of discrete ranges. For the top income interval, which is censored above 250,000 USD, we applied the methodology of [40], which approximates the upper part of the income distribution by extrapolating based on a Pareto distribution. Doing so suggested coding our top income interval as 496,124 USD. The bottom interval (censored at 35,000 USD) was coded as 30,000 USD, while all remaining intervals were coded at their midpoint. The resulting mean household income in our sample was approximately 171,000 USD. Twenty-six percent of respondents indicated that they were retired, and the mean household had 2.45 members in the household. Finally, self-reported political affiliations indicated that approximately half of our sample considered themselves conservative, while $15 \%$ considered themselves liberal. The remaining respondents identified as politically moderate or "None of the above".

Forty-one percent of the respondents claimed to be new to the coast (not surprising, since our survey focused on recent home buyers), while 35\% indicated they had lived on or near the coast for most or all of their life. Personal flood history and associated damages were elicited. Most respondents had not personally sustained any home damage due to flooding; $15 \%$ had sustained flood damage, and 3\% had sustained flood damage more than once. The average level of damage suffered was 31,800 USD.

\subsection{Expectations and Perceptions}

The survey measured individual expectations of natural and economic phenomena, including the likelihood of various types of disaster assistance. These data were Likert-scale measures converted into binary indicators, with a response of 3 or greater being considered "in accord" with a statement. Seventy-seven percent agreed that erosion will get worse in the future; sixty-one percent agreed that coastal storms will be worse in the future, and fifty-eight percent agreed that parts of the coast will need to embrace some form of managed retreat in the future. Additionally, 54\% expected coastal armoring to be effective in mitigating future damage of personal property. Individuals were asked what type of fiscal disaster aid they would expect in the event of a major hurricane strike near their home, including public aid to rebuild infrastructure and beaches (expected by 58\%) and personal aid for rebuilding personal property in the form of low-interest loans (expected by 51\%) and federal- or state-issued grants (expected by $35 \%)$.

Turning to measures of risk perception, the mean respondent expected just over 10 Category 3 (or greater) hurricanes to strike their community over the next 50 years. The median value was 5 , and slightly over half of all respondents expected 5 or fewer. Mapping the expected hurricane frequencies to a probability suggests an average annualized probability of 0.19 . Figure 1 depicts the empirical distribution 
of storm counts. For reference, the National Oceanic and Atmospheric Administration (NOAA) calculates the historical return period for a major hurricane to be about 33 years for Glynn County.

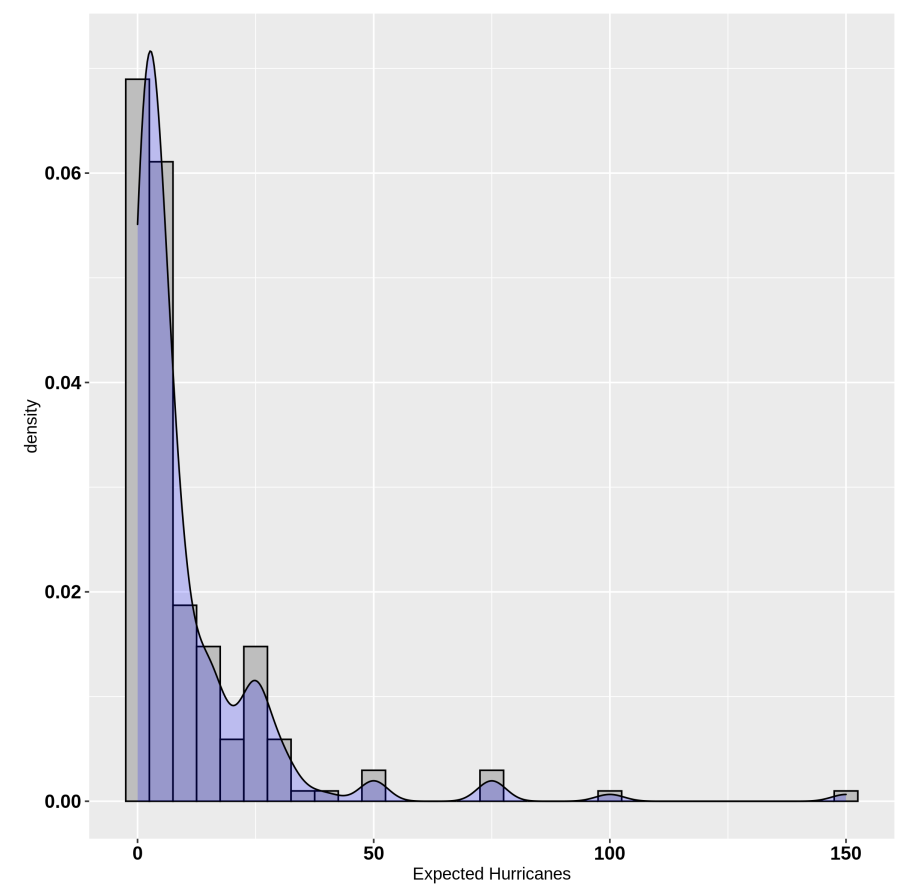

Figure 1. Expected major hurricanes over 50 years.

In addition to expectations on the frequency of future hurricanes, respondents were also asked to indicate how much damage they would expect their home to sustain (as a percentage of structure value) if a Category 3 hurricane was to directly strike Glynn County. Damage estimates were elicited on a five-point scale ranging from " $0-20 \%$ " up to " $81-100 \%$ ". Figure 2 reports the distribution of responses, where most respondents expected damages of " $21-40 \%$ " of home structure value. Coding each interval at its midpoint and taking an average suggests that the mean respondent expected damages that were equal to $43 \%$ of their home structure value.

Figure 3 reports the distribution of lottery choices from our risk preference instrument and the corresponding implied coefficients of relative risk aversion (CRRA). Roughly half of the respondents chose not to wager their incentive payment, which implied a CRRA of at least 0.85 , which is considered highly risk averse. About $20 \%$ chose the riskiest lottery, which corresponds to risk-loving behavior $(\mathrm{CRRA}<0)$, and the remaining respondents chose lotteries that all correspond to various levels of risk aversion or risk neutrality. The mean risk preference parameter was 0.49 , indicating moderate risk aversion. 


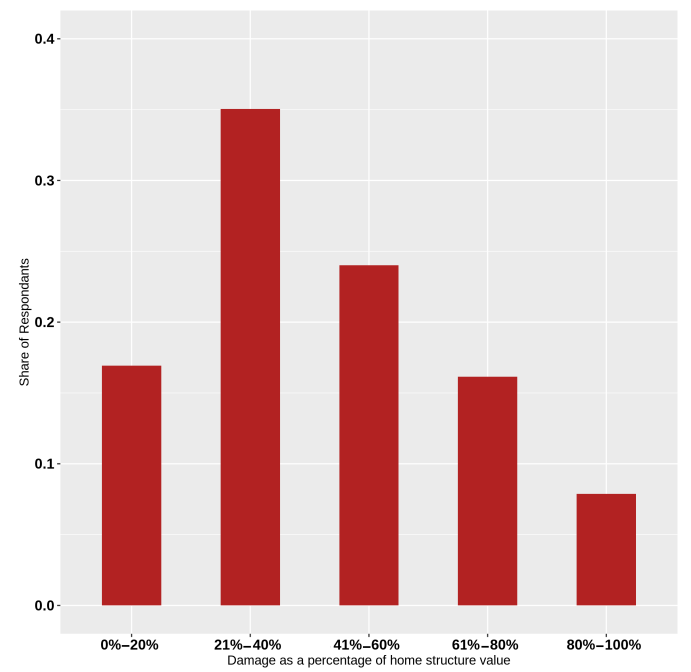

Figure 2. Expected major hurricane damage.

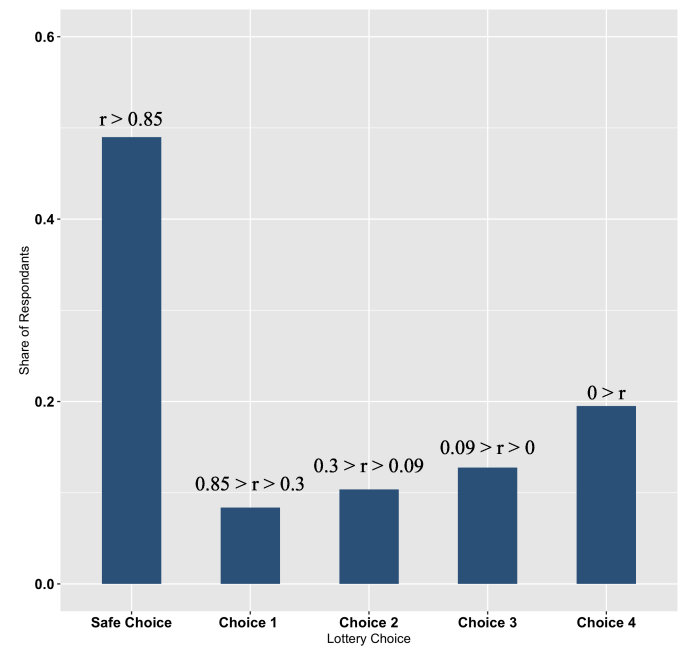

Figure 3. Elicited risk preferences.

Lastly, we explored emotional dimensions of risky decisions by measuring worry across various domains using a four-point scale. An individual was defined as "being worried" if they answered with a 3 or greater. Our primary purpose was to measure worry about risk to property and finances from natural hazards, but to reduce saliency and ameliorate any focusing illusions, we embedded these topics among other potential worries (e.g., health, safety, finance, social, and personal issues, defined over both individual and family effects). Forty-six percent of the respondents reported worrying about the loss of their home as a result of a natural disaster. If worry or dread drive insurance demand, this measure of worry may correlate with insurance coverage.

\section{Empirical Methods}

\subsection{Theoretical Motivation}

Our empirical analysis was motivated by canonical economic theory concerning decision-making under risk and uncertainty, which is largely based on expected utility theory [41,42]. Expected utility theory 
(EUT) posits the decision-maker's utility as an increasing function over wealth, where end-state wealth is uncertain due to some underlying stochastic process. The decision-maker's expected utility is derived by calculating the utility of wealth over all possible end-state wealth levels and weighting each possible outcome by its likelihood of occurring (the likelihood of occurrence for any given outcome could either be an objective metric or a subjective metric (i.e., a subjective probability) that is influenced by the individual's unique beliefs and experiences). If the decision-maker faces a choice that alters wealth in different states of the world, EUT suggests that the choice will be made that maximizes the decision-maker's expected utility. In the EUT framework, the demand for insurance is primarily motivated by the assumption that individual agents tend to be risk averse, meaning that their utility function over wealth is concave. This implies that the agent will prefer choices that have slightly lower expected utilities if a lower variance in potential end-state wealth accompanies the choice. The purchase of insurance lowers variance in end-state wealth by compensating the individual in the event of a catastrophic loss, thus mostly preserving end-state wealth. More formally, the expected utility of an individual agent with insurance can be written as:

$$
E\left[U_{i n s}\right]=\int_{0}^{L} p(l) U(W-l+C-D-P) \mathrm{dl},
$$

where $p(l)$ is the probability of a loss of magnitude $l$ that falls between 0 and $L$. W is the level of initial wealth, $C$ the level of insurance coverage, $D$ the deductible amount, and $P$ the insurance contract premium. This specification implicitly assumes $l>C$ and $l>D$. In reality, losses that are below the coverage level or deductible level are likely to occur, which could be represented by additional integrands, but we ignore those here for simplicity, since Equations (1) and (2) are only motivational and are not used to directly specify our estimating equations. Similarly, the expected utility of the same agent without insurance can be written as:

$$
E\left[U_{\text {unins }}\right]=\int_{0}^{L} p(l) U(W-l) \mathrm{dl} .
$$

Traditional EUT suggests that the agent will seek insurance if $E\left[U_{\text {ins }}\right]>E\left[U_{\text {unins }}\right]$; however, the EUT is often combined with other theoretical structures, such as random utility theory, which allows for utility to be separable into a deterministic and random component. This approach can rationalize deviations from the predictions of EUT that often occur in observed behavior [43].

Rather than imposing the structure presented in Equations (1) and (2) or another variant of decision theory (e.g., prospect theory), we take a reduced-form approach, exploring conditional correlations of plausibly exogenous variables on our key endogenous variables-a binary indicator of flood insurance purchase and a coverage measure (ratio of cover to structure value). We do, however, draw on the theory outlined above to appropriately specify our reduced-form estimating equations.

Overall, the expected utility of a decision is primarily determined by the agent's perception of the likelihood of outcomes occurring (i.e., subjective probability), the end-state wealth, and the individual's level of risk aversion. These components and measures, however, and are not exogenously determined, meaning that any covariates that may influence any one of these components should be included in a reduced-form analysis of flood insurance demand (we note that many generalized alternatives to EUT have been proposed in the literature; however, they almost all maintain the decision-maker's utility as a multiplicative relationship between likelihood and outcomes [22]; thus, using any of these alternative theories would motivate the same specification of our reduced-form analysis). For example, specifics of insurance contracts influence end-state wealth, and demographics likely influence initial wealth and, thus, also influence (indirectly) end-state wealth. Objective risk metrics, expectations, perceptions, and past experiences are all likely determinants of an individual's subjective probability of each loss magnitude. Finally, attitudes towards risk influence the utility achieved from various end-state wealth levels. 
In addition to a theoretically motivated reduced-form analysis, we also assess the variation in flood insurance uptake and the relevance of our survey measures using a form of Bayesian variable selection. We have a wide array of potential covariates that could plausibly influence the demand for flood insurance. The array of survey measures stems from different disciplinary approaches to analysis of risk under uncertainty and may suffer from multi-collinearity (in addition to other potential problems). To explore the appropriateness of including any of a surfeit of covariates in the estimating equations for flood insurance demand, we employ several Bayesian econometric models that make use of stochastic search variable selection (SSVS) [44]. This method allows us to assign a marginal posterior inclusion probability to each covariate, which provides insight into which regressors are most likely to be included in the model with the best overall fit. The SSVS analysis is antithetical to our theoretically motivated reduced-form analysis in the sense that it is atheoretical. Ideally, the two approaches would suggest equivalent specifications, implying that the model suggested by economic theory is likely to be one that also maximizes overall model fit. We compare the specifications of each approach in the results section. The remainder of this section details the estimation procedure used for both the reduced-form model and the SSVS model.

\subsection{Reduced-Form Regression Analysis}

The reduced-form models we consider are a standard probit model for the binary decision to purchase flood insurance and a beta regression where the outcome of interest is flood insurance coverage (as a proportion of structure value). Both of these models are estimated via Maximum Likelihood and include covariates that the canonical theory of decision-making under risk and uncertainty would suggest are relevant. We include full-coverage flood insurance premiums (in the U.S., spatial variation in flood insurance eligibility (and premiums) does exist and is a consideration for analysis of flood insurance demand; part of the variation in premiums is determined at the community level, based on the NFIP's Community Rating System (CRS); the CRS measures a municipality's level of flood preparedness, information provision, and flood risk mitigation efforts, and the program adjusts premiums based on points allocated for overall efforts at the local level; our sample is drawn from a single community (Glynn County), which had a CRS score of 7 at the time of our survey, making flood zone residents eligible for a $15 \%$ discount on standard flood insurance contracts ( $5 \%$ for residents outside a flood zone); since our sample is drawn from a single community, all residents are eligible for flood insurance and face the same premium pricing structure, meaning that we can safely ignore heterogeneity in eligibility and premium discounts that would be present in a broader context), household income, the share of wealth in coastal real estate, the risk preference measure (CRRA value), elicited probability of a hurricane, and expected damage. To account for affect, we include a dummy variable for worry over loss of home. To account for flood experience, we include an interaction term that is zero for households that have experienced no past flood losses and is equal to the size of the monetary loss for those that have. Other control variables include location in an SFHA, distance from the shoreline, age, and education.

\subsection{Stochastic Search Variable Selection}

Like our reduced-form models, our SSVS specification is also based on a binary probit (for binary flood insurance status) and a beta regression (for coverage level). The binary probit model $(1=$ flood insurance; $0=$ not) takes the standard form, as defined in Equation (3), where $X$ is a vector of $p$ potential covariates and $\theta$ is a parameter vector. To implement SSVS, each element of $\theta$ is defined as: $\theta_{j}=I_{j} \beta_{j}[45]$, where $I_{j}$ is a Bernoulli distributed indicator variable and $\beta_{j}$ is a normally distributed parameter that captures the effect of $x_{j}$ on the probability that $y=1$. When $I_{j}=0, x_{j}$ is effectively excluded from the model, whereas when $I_{j}=1, x_{j}$ is included and has estimated effect size $\beta_{j}$. Equation (3) is estimated using Markov-Chain Monte Carlo (MCMC), where the mean parameter value of each $I_{j}$ can be interpreted 
as the marginal posterior inclusion probability (i.e., the probability that $x_{j}$ is in the true reduced-form model).

$$
P\left(y_{i}=1 \mid X_{i}\right)=\Phi\left(\alpha+\sum_{j=1}^{p} \theta_{j} x_{i, j}+\epsilon_{i}\right)
$$

We take an agnostic view of the degree of sparseness that the model should have (i.e., how many covariates the true reduced-from model should have). Additionally, we utilize a random-effects approach in estimation of $\beta_{j}$, which allows the prior variance of $\beta_{j}$ to be estimated rather than specified. Both of these specification decisions increase model flexibility and reduce the chance that poorly chosen priors influence the results. Thus, prior (and hyper-prior) distributions for the model are assigned as follows:

$$
\begin{gathered}
I_{j} \sim \operatorname{bernoulli}(\rho) \\
\rho \sim \operatorname{beta}(10,10) \\
\beta_{j} \sim N(0, \tau) \\
\tau \sim \operatorname{gamma}(1,0.1) \\
\alpha \sim N(0,100)
\end{gathered}
$$

The indicator variables, $I$, are assigned a Bernoulli prior with probability $\rho$, which can be interpreted as a parameter on model sparsity. For example, assigning $\rho=0.2$ implies an a priori belief that about $20 \%$ of the covariates under consideration should be in the true model. Rather than assigning a value to $\rho$, we let $\rho$ be a parameter to estimate and assign a beta distribution as the prior with both shape parameters set to 10. This distribution is symmetric around 0.5 and places over $99 \%$ of the probability mass of $\rho$ between 0.2 and 0.8 , which is reflective of a belief that the true model will not contain less than $20 \%$ and not more than $80 \%$ of the covariates under consideration. The beta parameters, $\beta_{j}$, are assigned a normally distributed prior with variance $\tau$, where $\tau$ is a parameter to be estimated and is assigned a gamma-distributed prior with shape parameters set to 1 and 0.1, respectively. Finally, the constant term $\alpha$ is assigned a weakly informative normally distributed prior with mean 0 and variance of 100 .

We analyze flood insurance coverage levels by expressing coverage as a percentage of structure value. We use a beta regression to model this dependent variable, which is appropriate for a fractional response. To account for the fact that 0 and 1 are included in our outcome of interest, we apply the commonly used transformation $\frac{(y(n-1)+0.5)}{n}$ (where $\mathrm{y}$ is the fractional outcome and $n$ is the sample size) to map our outcome variable to the $(0,1)$ interval. The procedure for estimating the beta regression is analogous to the probit specification. The log-likelihood for the beta regression is defined in Equation (4), where $\mathrm{B}($.$) is the beta$ function, $\phi$ is a parameter to be estimated, and $\mu=g^{-1}\left(\alpha+\sum_{j=1}^{p} \theta_{j} x_{i, j}+\epsilon_{i}\right)$, where $g($.$) is a link function that$ maps the input to the unit interval. We use the logit function for $\mathrm{g}($.$) in our specification. Prior distributions for$ the beta regression are the same as those used for the probit specification.

$$
f\left(y_{i} \mid \mu, \phi\right)=\frac{y_{i}^{(\mu \phi-1)}\left(1-y_{i}\right)^{((1-\mu) \phi-1)}}{B(\mu \phi,(1-\mu) \phi)}
$$

All specifications were estimated using MCMC. We ran 210,000 iterations of the Metropolis-Hastings algorithm, discarding the first 10,000 iterations as a "burn-in" and applying a thinning interval of 10 to reduce auto-correlation. For each parameter, trace, density, and auto-correlation plots were visually inspected for any sign of non-convergence. Additionally, we applied the Gelman-Rubin diagnostic and used the common potential scale reduction factor (PSRF) value of 1.1 as the threshold for convergence [46]. 


\section{Results}

Table 2 reports marginal inclusion probabilities from our Bayesian variable selection specifications. Generally, variables that economic theory would suggest should be included in an analysis of insurance demand tend to have high marginal inclusion probabilities. For the model focused on flood insurance status, higher education has the highest inclusion probability at $92 \%$ followed by SFHA status at $91 \%$. Being able to correctly identify the flood zone in which one's home is located was also deemed to be an important predictor, with an inclusion probability of $81 \%$. Other covariates deemed important were: coastal home value as a share of total net worth (inclusion probability of $74 \%$ ); risk preferences (inclusion probability of $64 \%$ ); and the belief that coastal retreat will be necessary in the future (inclusion probability of $54 \%$ ). The two variables related to hurricane expectations-expected damage and the probability of a hurricane strike-are also more likely than not in the true model, with inclusion probabilities of 57\% and $52 \%$, respectively. Many of the remaining covariates under consideration have non-trivial inclusion probabilities, but are all more likely to be excluded from the true model than included. Of note, expectations of individual disaster grants are the most likely of the charity hazard variables to be included (probability of $44 \%$ ), followed by public assistance (35\%) and reconstruction loans (31\%). Other variables that we expected to be important in the flood insurance decision, like worry of loss of home and income, exhibit low inclusion probabilities.

Table 2. Stochastic search variable selection inclusion probabilities.

\begin{tabular}{|c|c|c|c|}
\hline \multicolumn{2}{|l|}{ Flood Insurance } & \multicolumn{2}{|l|}{ Flood Coverage } \\
\hline & Inclusion & & Inclusion \\
\hline Variable & Probability & Variable & Probability \\
\hline Higher Edu. & 0.921 & Knew Zone & 0.627 \\
\hline SFHA & 0.908 & SFHA & 0.599 \\
\hline Knew Zone & 0.813 & Expected Damage & 0.464 \\
\hline Wealth Share & 0.737 & CRRA & 0.457 \\
\hline CRRA & 0.64 & Wealth Share & 0.452 \\
\hline Expected Damage & 0.568 & Retreat & 0.438 \\
\hline Retreat & 0.539 & Higher Edu. & 0.426 \\
\hline Prob. Hurricane & 0.516 & Exp. Disaster Aid (Individual) & 0.392 \\
\hline Armoring & 0.453 & Prob. Hurricane & 0.383 \\
\hline Exp. Disaster Aid (Individual) & 0.44 & Life Time Resident & 0.382 \\
\hline Employed (Part Time) & 0.415 & Armoring & 0.367 \\
\hline Life Time Resident & 0.379 & Employed (Part Time) & 0.365 \\
\hline White & 0.372 & White & 0.34 \\
\hline Exp. Disaster Aid (Public) & 0.355 & Liberal & 0.328 \\
\hline $\mathrm{Km}$ to Coast & 0.338 & Conservative & 0.323 \\
\hline Liberal & 0.331 & Female & 0.321 \\
\hline Moderate & 0.31 & Worse Storms & 0.312 \\
\hline Exp. Disaster Aid (Loans) & 0.307 & Exp. Disaster Aid (Loans) & 0.31 \\
\hline Worse Erosion & 0.302 & Household Size & 0.307 \\
\hline Female & 0.302 & Retired & 0.304 \\
\hline Conservative & 0.291 & Worse Erosion & 0.302 \\
\hline Retired & 0.29 & Moderate & 0.296 \\
\hline Worse Storms & 0.286 & Worry (Home Loss) & 0.288 \\
\hline Worry (Home Loss) & 0.283 & New To Coast & 0.286 \\
\hline New To Coast & 0.278 & Exp. Disaster Aid (Public) & 0.282 \\
\hline Household Size & 0.254 & $\mathrm{Km}$ to Coast & 0.181 \\
\hline Income & 0.158 & Age & 0.014 \\
\hline Age & 0.015 & Income & 0.002 \\
\hline Flood Premium (Calculated) & 0.000 & Flood Premium (Calculated) & 0.000 \\
\hline Flood Damage & 0.000 & Flood Damage & 0.000 \\
\hline
\end{tabular}


The specification focused on flood insurance coverage level suggests that far fewer of the considered variables should be included in the true reduced-form model. Being aware of one's own flood zone and residing in an SFHA are the only two variables in this specification that had inclusion probabilities greater than $50 \%$. This suggests that explaining flood insurance status is a more tractable task than explaining the level of coverage. Nonetheless, risk preference and risk perception (expected damage and hurricane probability) are in the top 10 variables for inclusion probability. Additionally noteworthy is that the flood insurance premium has a negligible inclusion probability in each model; this is in stark contrast to what economic theory would predict.

Turning to regression analysis, overestimation of the magnitude of effects is likely to occur if the same data are used for both specifying the model (SSVS) and the individual effects of the selected covariates [47]. Thus, we largely ignore the variable selection results in specifying regression models, and instead select parsimonious specifications populated by variables that theory suggests should influence flood insurance demand. Our specified models and the variables suggested by SSVS, however, are quite similar due to the SSVS results placing a high inclusion probability on many of the variables dictated by economic theory. This is a partially validation of our theoretical motivations, since the two independent approaches suggest similar reduced-form specifications. It would be concerning if the SSVS procedure assigned low inclusion probabilities to many variables that economic theory suggests should be included.

Table 3 reports coefficient estimates from our reduced-form models estimated via maximum likelihood. Overall, many of the estimated coefficients are significantly correlated with flood insurance decisions and have the anticipated sign. Individuals residing in an SFHA are more likely to hold a flood insurance policy (marginal effect of 23\%) and exhibit greater levels of coverage (marginal effect of 14.5\%). As home value as a share of total wealth increases, the probability of insuring and coverage level both increase (marginal effects of $58 \%$ and $27 \%$, respectively). Experimentally elicited risk preferences are also significantly correlated with flood insurance decision. Increased CRRA coefficients correspond to both higher probability of insuring (marginal effect of 21\%) and increased levels of coverage (marginal effect of $12 \%$ ). With respect to hurricane risk perceptions, expected damage appears to explain some of the variation in flood insurance decisions (marginal effect of $32 \%$ for the uptake model and marginal effect of $25 \%$ in the coverage model), whereas beliefs about the frequency of future storms do not. Other significant variables include educational attainment and household income, which were found to increase the probability of insuring (marginal effects of $17 \%$ and $0.07 \%$, respectively), but no significant effect was detectable for coverage level. 
Table 3. Estimates for flood insurance demand.

\begin{tabular}{|c|c|c|}
\hline & Flood Insurance Status & Flood Coverage Level \\
\hline & Probit & Beta Regression \\
\hline SFHA & $\begin{array}{c}0.8385^{* *} \\
(0.3451)\end{array}$ & $\begin{array}{c}0.6138^{* *} \\
(0.2582)\end{array}$ \\
\hline Higher Edu. & $\begin{array}{c}0.6046^{* * *} \\
(0.2252)\end{array}$ & $\begin{array}{c}0.3147 \\
(0.2102)\end{array}$ \\
\hline Wealth Share & $\begin{array}{c}2.0904^{* * *} \\
(0.5830)\end{array}$ & $\begin{array}{l}1.1280 * * \\
(0.4886)\end{array}$ \\
\hline CRRA & $\begin{array}{c}0.7545^{* * *} \\
(0.2813)\end{array}$ & $\begin{array}{c}0.4915^{* *} \\
(0.2450)\end{array}$ \\
\hline Expected Damage & $\begin{array}{c}1.1468 * * \\
(0.4893)\end{array}$ & $\begin{array}{l}1.0690 * * \\
(0.4286)\end{array}$ \\
\hline Prob Hurricane & $\begin{array}{l}-0.2813 \\
(0.4393)\end{array}$ & $\begin{array}{l}-0.1749 \\
(0.4004)\end{array}$ \\
\hline Flood Premium (Calculated) & $\begin{array}{l}-0.0000 \\
(0.0001)\end{array}$ & $\begin{array}{c}-0.0001 \\
(0.0001)\end{array}$ \\
\hline Income & $\begin{array}{c}0.0023 * * * \\
(0.0009)\end{array}$ & $\begin{array}{c}0.0001 \\
(0.0007)\end{array}$ \\
\hline Worry (Home Loss) & $\begin{array}{l}-0.0372 \\
(0.2357)\end{array}$ & $\begin{array}{l}-0.0385 \\
(0.2065)\end{array}$ \\
\hline Exp. Disaster Aid (Individual) & $\begin{array}{l}-0.2990 \\
(0.2160)\end{array}$ & $\begin{array}{l}-0.2538 \\
(0.1975)\end{array}$ \\
\hline Flood Damage & $\begin{array}{c}0.0000 \\
(0.0000)\end{array}$ & $\begin{array}{l}-0.0000 \\
(0.0000)\end{array}$ \\
\hline Km to Coast & $\begin{array}{l}-0.0405 \\
(0.0381)\end{array}$ & $\begin{array}{l}-0.0227 \\
(0.0351)\end{array}$ \\
\hline Age & $\begin{array}{c}0.0066 \\
(0.0075)\end{array}$ & $\begin{array}{c}0.0035 \\
(0.0066)\end{array}$ \\
\hline Constant & $\begin{array}{c}-1.9931^{* * *} \\
(0.7028)\end{array}$ & $\begin{array}{c}-1.2546^{* *} \\
(0.6097)\end{array}$ \\
\hline Observations & 210 & 210 \\
\hline LL & -102.821 & 308.443 \\
\hline AIC & 233.641 & -586.886 \\
\hline BIC & 280.501 & -536.680 \\
\hline
\end{tabular}

\section{Discussion}

Management of weather risks under changing climate will require a deep understanding of integrated natural and social sciences. Arguably, our knowledge of human dimensions of risk lags significantly behind climate science and engineering. Effective risk management entails exploration of novel and creative adaptation policies, while also finding deeper knowledge of individual decisions that ultimately influence vulnerability. To this end, we seek a broad collection of information on individual attitudes, beliefs, preferences, and expectations that will help us understand decision-making under risk. We draw from economics, sociology, and psychology in formulating metrics to measure attitudes and beliefs about coastal development and climate change; expectations of environmental change, market forces, and government policy; subjective perceptions of weather risk; risk preferences; and emotional determinants of risky behavior. Notably, our sample is drawn from a coastal population that has had comparatively less historical exposure to natural hazards and has objective risk measures that are somewhat lower than other coastal areas in the southeastern United States. The area was recently affected by two hurricanes, however. This provides a snapshot of the determinants of decision-making under risk in the context of (at least perceived) historically low risk, which can provide insight into evolving climate risks.

Our data suggest that the majority of coastal residents in our sample believe that coastal hazards will be worse in the future. The average respondent in our survey expected 10.6 major hurricanes to pass in 
close proximity to Glynn County over the next 50 years, a number that is much higher than estimated hurricane return periods would suggest [30] (the NOAA estimates the return period for a major hurricane to be approximately 33 years for Glynn County). This result contrasts with past work on the Gulf Coast, which found (using the same metric) a mean response of 6.86 for expected major hurricanes occurring over the next 50 years, though those data were collected almost 10 years prior [28]. We note that coastal Georgia was adversely affected by Hurricanes Matthew (2016) and Irma (2017), which may have caused updating of beliefs or enhanced perceptions of risk. Additionally, these results may simply reflect the trend of an increasing number of hurricanes and other flooding events over the last several decades, which individuals internalize and extrapolate into the future.

Many private-sector actions, such as the locations of neighborhoods, the density and quality of buildings, installation of mitigation measures, and uptake of flood insurance, have significant implications for coastal vulnerability. As such, the public sector often imposes regulations and restrictions on these actions. While we are not able to examine all of these factors, our data do include information on household flood insurance. Thus, we took two non-structural approaches to exploring determinants of flood insurance demand. We used Bayesian variable selection methods to let the data tell us which of a bevy of factors are correlated with uptake and coverage levels, and we estimated regression models to assess reduced-form correlations.

In both the Bayesian variable selection and regression analysis, we find that expected hurricane damages significantly correlate with flood insurance status and level of coverage, whereas expected frequency of future hurricanes exhibits much less correlation (one plausible explanation for the insignificant effect of expected hurricane frequency on flood insurance decisions is potential heterogeneity in how individuals process experiences with natural hazards; as has been noted by [48], the "gambler's fallacy" and the "availability heuristic" predict diverging behaviors in response to a recently experienced natural disaster-the former suggests that individuals believe the future likelihood of a low-probability event is less likely following the occurrence of the event, a bias rooted in a misunderstanding of probabilistic independence, while the latter suggests that perceived likelihood increases following the occurrence of the event due to increased salience; complicating matters, both biases have been shown to be present with varying degrees of prominence depending on the subset of the population [48], meaning that even similar past experiences may very well be prompting competing effects to manifest). Existing literature on the role that individual risk perceptions have in flood mitigation behavior has reached mixed conclusions, with many empirical studies finding no evidence of a relationship between the two (see [49] for a review). Notably, many previous studies that model mitigation or insurance behavior do not decompose risk perception into probability and consequences, and instead focus on one or the other [49]. Our results, however, suggest that the distinction between probability and consequences is an important one for future work on the role that risk perceptions play in mitigation of natural hazards.

It is also possible that our data suffer from measurement issues associated with open-ended assessment of the expected number of hurricanes over a given interval of time. Studies have shown that people have a difficult time responding to probability queries [50-52]. Building on previous research [28], we utilized the storm count over 50 years, but it is also possible that this approach induces difficulties. Future research should explore whether discrete (i.e., Yes/No) responses to stated numbers of storms produce more valid estimates of the distribution of hurricane expectations. There is ample evidence that this approach is more effective (in terms of reducing bias and increasing item response) in assessing willingness to pay for non-market commodities [53,54].

All models suggest that risk preferences play a significant role in insurance demand. The Bayesian model selection indicates that these measures predict flood insurance uptake (and, to a lesser extent, coverage), and our regression results suggest that more risk-averse households are more likely to hold flood insurance and exhibit greater levels of coverage. This evidence of internal validity suggests that 
monetary risk experiments defined over the domain of weather outcomes may be effective in producing estimates of risk aversion for flood (and possibly other kinds of disasters) insurance. Future research should assess the external validity of these estimates.

One would expect that the exposure of wealth to risk would increase demand for insurance and mitigation. Our survey included a measure of the proportion of household wealth that was in coastal property exposed to storm risk. We find that this variable exhibits a high inclusion probability in Bayesian analysis and has positive correlation with flood insurance uptake and coverage levels. This suggests that home equity and/or coastal exposure are motivating factors in purchase of flood insurance. Wealth share exhibits higher inclusion probabilities than household income in the Bayesian selection models and greater correlation than income in regression models.

The calculated flood insurance premium for full structure coverage exhibited low inclusion probabilities in the Bayesian analysis and low statistical significance in the regression analysis. Previous literature has noted the difficulties in identifying flood insurance price effects [55-57]. This problem appears to be particularly severe in our new homeowner dataset and complicates standard economic analysis. Price analysis can suffer from endogeneity, since the premium reflects the level of coverage and deductible chosen. Our premium measure, however, was specified for total coverage and the most common premium level [17]. As such, our measurement issues likely stem from correlation of pricing with risk and are a limitation to be addressed in future research.

\section{Conclusions}

The purpose of this study is to provide a contemporary profile of coastal residents' risk posture by characterizing their attitudes, perceptions, beliefs, and expectations related to coastal hazards and exploring how these correlate with flood insurance uptake. We do so by administering surveys to recent home buyers in Glynn County, GA and eliciting a variety of responses to construct a rich profile of each respondent's characterization of coastal living and perceptions of risk. Although this paper is not the first to utilize individual survey data in a natural hazard context, it is notable in that it targets U.S. coastal residents in an area with relatively low historical natural hazard exposure. Analysis of our data suggests that many respondents expect exacerbation of coastal hazards in the future, including greater destructive power of storms, increased rates of erosion, and greater frequency of major hurricanes (significantly greater than what historical data would suggest). Modeling flood insurance decisions as a function of elicited responses suggests that future expectations and beliefs play a role in hazard mitigation decisions. Notably, we find that greater expected damages from a major hurricane significantly impact flood insurance decisions; contrarily, we find no significant relationship between expected hurricane frequency and flood insurance decisions. Measures of risk aversion are robust predictors for flood insurance decisions, as are flood zone location and the share of wealth in coastal property exposed to storm risk.

Other covariates that would normally be included in models of flood insurance demand, like flood premium and household income level, are not significant predictors of demand in our results. Problems associated with identification of price effects, particularly related to correlation of risk factors and price level, are well documented and will require special attention to research design (e.g., spanning time or space to induce exogenous variation in premium levels). The lack of explanatory power for variables like hurricane probability and worry of loss of home may reflect poor measurement in our survey instrument; this is a direction for future research. Other factors that are less common in economic analysis, including accurate knowledge of flood zones and attitudes toward community hazard mitigation projects, prove to be robust predictors of flood insurance demand. These factors are likely accounting for underlying, latent constructs, like risk cognizance and public risk management attitudes, which deserve further exploration in analysis of flood insurance demand. 
From a policy perspective, our results offer several insights. First, standard models of decision-making under risk provide some guidance in understanding flood insurance coverage; measures of risk perception and risk tolerance (preference) are robust predictors of demand for flood insurance. While risk tolerance is often viewed as given, risk perceptions can evolve with information and experience. Our data suggest that recent home coastal home buyers are fairly pessimistic about future coastal risks and the livelihood of coastal communities. Thus, coastal residents may be primed for new governance initiatives that address their concerns; the majority of respondents feel that local policies are not adequately managing risk.

Second, individual awareness and attitudes, particularly regarding flood risk and potential management strategies, are likely to be important sources of underlying heterogeneity in willingness to purchase insurance and mitigate risks. Leveraging participation and engagement among particular members of coastal communities is likely to be important in devising new governance initiatives.

The results presented here contribute to understanding of individual expectations, beliefs, and perceptions related to natural hazards and how those individual characteristics effect hazard mitigation decisions. As climate change and associated sea level rise alter objective risks for coastal communities, understanding the nuanced differences in how different populations respond to changes in those objective risks will be an important consideration for future policy discussions. Additionally, since individual perceptions and expectations of natural hazard risk are important determinants of mitigation adoption, gaining insight into how quickly expectations change in response to changes in objective risk metrics will be particularly important in moving forward. Longitudinal studies would be especially helpful in this regard and remain as an opportunity for future research.

Author Contributions: Both authors share responsibility for all aspects of this research paper. Both authors have read and agreed to the published version of the manuscript.

Funding: This research was funded by the National Science Foundation: Coupled Natural-Human Systems-Award ID 1715638.

Conflicts of Interest: The authors declare no conflict of interest.

\section{Appendix A. Variable Descriptions}

Table A1. Variable Descriptions.

\begin{tabular}{lcl}
\hline Variable & Type & Description \\
\hline Panel A: Insurance & Binary & $=1$ if homeowner has flood insurance (self-reported) \\
\hline Flood Policy & Continuous & Calculated full-coverage annual flood insurance premium \\
\hline Flood Premium (Calculated) & Binary & $\begin{array}{l}=1 \text { if respondent indicated that their Glynn County home was their } \\
\text { primary residence }\end{array}$ \\
\hline Primary Home & Binary & $=1$ if the home is located in an SFHA (based on GIS and latitude/longitude) \\
\hline SFHA & Binary & $=1$ if self-reported SFHA status matches actual SFHA status \\
\hline Knew Zone & Ordered Categorical & $\begin{array}{l}\text { Self-reported home value's share of net worth ranging from } \\
\text { "less that 20\%" up to "81-100\%" }\end{array}$ \\
\hline Wealth Share & Continuous & Kilometers from respondent's home to coast \\
\hline Km to coast & Binary & $=1$ if respondent indicated being female \\
\hline Panel B: Demographics & Binary & $=1$ if respondent indicated their race as being white \\
\hline Female & Ordered Categorical & Respondent's age: ranging from "18-24" up to “75+" \\
\hline White & Binary & $=1$ if respondent indicated that they have a bachelor's degree of higher \\
\hline Age &
\end{tabular}


Table A1. Cont.

\begin{tabular}{|c|c|c|}
\hline Variable & Type & Description \\
\hline Income & Ordered Categorical & $\begin{array}{l}\text { Household income: ranging from "less than } 35,000 \text { USD" up to } \\
\text { "more than } 250,000 \text { USD" }\end{array}$ \\
\hline Retired & Binary & $=1$ if respondent indicated that they were retired \\
\hline Household Size & Discrete & Number of members in household \\
\hline Conservative & Binary & $=1$ if respondent indicated that they were politically conservative \\
\hline New to Coast & Binary & $=1$ if respondent indicated that they were new to the coast \\
\hline Life Time Resident & Binary & $\begin{array}{l}=1 \text { if respondent indicated that they have lived on the coast } \\
\text { for most or all of their life }\end{array}$ \\
\hline Coastal Vet. & Binary & $\begin{array}{l}=1 \text { if respondent indicated that they had lived on the } \\
\text { coast for all or most of their life }\end{array}$ \\
\hline Flood Damage & Continuous & $\begin{array}{l}\text { The amount of the most recent flood damage } \\
\text { (in dollars) the respondent had incurred }\end{array}$ \\
\hline Prior Flood & Discrete & $\begin{array}{l}=1 \text { if respondent's home has been } \\
\text { damaged from flooding }\end{array}$ \\
\hline \multicolumn{3}{|c|}{ Panel C: Expectations and Perceptions } \\
\hline Worse Erosion & Binary & $=1$ if respondent expected that erosion will get worse \\
\hline Worse Storms & Binary & $=1$ if respondent expected that coastal storms will get worse. \\
\hline Armoring & Binary & $\begin{array}{l}=1 \text { if respondent expected that coastal armoring will protect } \\
\text { personal property }\end{array}$ \\
\hline Retreat & Binary & $\begin{array}{l}=1 \text { if respondent expected that parts of the coast will need to } \\
\text { embrace coastal retreat }\end{array}$ \\
\hline Exp. Disaster Aid (Individual) & Binary & $\begin{array}{l}=1 \text { if respondent expected government grants to be } \\
\text { available for rebuilding personal property after a } \\
\text { hurricane }\end{array}$ \\
\hline Exp. Disaster Aid (Public) & Binary & $\begin{array}{l}=1 \text { if respondent expected government assistance to } \\
\text { help rebuild infrastructure and beaches after a } \\
\text { hurricane }\end{array}$ \\
\hline Exp. Disaster Aid (Loans) & Binary & $\begin{array}{l}=1 \text { if respondent expected access to low-interest loans } \\
\text { for rebuilding personal property after a hurricane }\end{array}$ \\
\hline Prob Hurricane & Continuous & $\begin{array}{l}\text { Annualized subjective probability of a hurricane strike based } \\
\text { on the number of Cat. } 3 \text { hurricanes expected to pass within } 30 \\
\text { miles over the next } 50 \text { years }\end{array}$ \\
\hline Expected Damage & Ordered Categorical & $\begin{array}{l}\text { Expected damage as a share of home value from Cat } 3 . \\
\text { hurricanes (1 indicates } 0-20 \% \text { up to } 5 \text { indicating } \\
81-100 \%)\end{array}$ \\
\hline CRRA & Ordered Categorical & Elicited CRRA value from the risk preference instrument \\
\hline Worry (Home Loss) & Binary & $\begin{array}{l}=1 \text { if respondent worried about the loss of their home } \\
\text { to natural disasters }\end{array}$ \\
\hline
\end{tabular}

\section{References}

1. NOAA. Billion-Dollar Weather and Climate Disasters; National Oceaninc and Atomospheric Administration: Silver Spring, MD, USA, 2020.

2. Boustan, L.P.; Kahn, M.E.; Rhode, P.W.; Yanguas, M.L. The Effect of Natural Disasters on Economic Activity in Us Counties: A Century of Data; Working Paper 23410; National Burea of Economic Research: Cambridge, MA, USA, 2019.

3. Gaiha, R.; Hill, K.; Thapa, G.; Kulkarni, V.S. Have Natural Disaster Become Deadlier. In Sustainable Economic Development: Resources, Environment and Institutions; Balisacan, A.M., Chakravorty, U., Ravago, M.L.V., Eds.; Academic Press: Oxford, UK, 2015; Chapter 23, pp. 415-442.

4. Kousky, C. Informing climate adaptation: A review of the economic costs of natural disasters. Energy Econ. 2014, 46, 576-592. [CrossRef] 
5. Kunreuther, H.C.; Michel-Kerjan, E.O. Climate Change, Insurability of Large-scale Disasters and the Emerging Liability Challenge; Working Paper 12821; National Burea of Economic Research: Cambridge, MA, USA, 2007.

6. USACE. National Levee Database; U.S. Army Corp of Engineers: Washington, DC, USA, 2020.

7. Kunreuther, H.C.; Pauly, M. Rules rather than discretion: Lessons from hurricane Katrina. J. Risk Uncertain. 2006, 33, 101-116. [CrossRef]

8. Landry, C.E.; Turner, D.; Petrolia, D.R. Flood Insurance Market Penetration and Expectations of Disaster Assistance; Working Paper 3371980; Social Science Research Network: Rochester, NY, USA, 2019.

9. Andor, M.A.; Osberghaus, D.; Simora, M. Natural Disaster and Governmental Aid: Is there a Charity Hazard? Ecol. Econ. 2020, 169, 106534. [CrossRef]

10. Davlasheridze, M.; Miao, Q. Does Governmental Assistance Affect Private Decisions to Insure? An Empirical Analysis of Flood Insurance Purchases. Land Econ. 2019, 95, 124-145. [CrossRef]

11. Kousky, C.; Michel-Kerjan, E.O.; Raschky, P.A. Does federal disaster assistance crowd out flood insurance? J. Environ. Econ. Manag. 2018, 87, 150-164. [CrossRef]

12. Kousky, C.; Kunreuther, H.C.; Lingle, B.; Shabman, L. The Emerging Private Residential Flood Insurance Market in the United States; Technical Report; Wharton Risk Management and Decision Processes Center: Philadelphia, PA, USA, 2018.

13. Czajkowski, J.; Kunreuther, H.C.; Michel-Kerjan, E.O. Quantifying Riverine and Storm-Surge Flood Risk by Single-Family Residence: Application to Texas. Risk Anal. 2013, 33, 2092-2110. [CrossRef]

14. Rees, R.; Wambach, A. The Microeconomics of Insurance. Found. Trends ${ }^{\circledR}$ Microecon. 2008, 4, 1-163. [CrossRef]

15. Alexander, M.; Priest, S.; Mees, H. A framework for evaluating flood risk governance. Environ. Sci. Policy 2016, 64, 38-47. [CrossRef]

16. Michel-Kerjan, E.O. Catastrophe economics: The national flood insurance program. J. Econ. Perspect. 2010, 24, 165-86. [CrossRef]

17. Michel-Kerjan, E.O.; Kousky, C. Come rain or shine: Evidence on flood insurance purchases in Florida. J. Risk Insur. 2010, 77, 369-397. [CrossRef]

18. Li, J.; Landry, C.E. Flood risk, local hazard mitigation, and the community rating system of the national flood insurance program. Land Econ. 2018, 94, 175-198. [CrossRef]

19. Bergsma, E. Geographers versus managers: Expert influence on the construction of values underlying flood insurance in the United States. Environ. Values 2016, 25, 687-705. [CrossRef]

20. Hunn, D.; Dempsey, M.; Zaveri, M. Most homes damaged by Harvey were outside flood plain, data show. Houston Chron. 2018. Available online: houstonchronicle.com/news/article/In-Harvey-s-delugemost-damaged-homes-were-12794820.php (accessed on 1 August 2020).

21. Wing, O.E.J.; Bates, P.D.; Smith, A.M.; Sampson, C.C.; Johnson, K.A.; Fargione, J.; Morefield, P. Estimates of present and future flood risk in the conterminous United States. Environ. Res. Lett. 2018, 13, 034023. [CrossRef]

22. Landry, C.E.; Ahmadiani, M.; Colson, G. Structural Empirical Analysis of Decisions under Natural Hazard Risk. In The Future of Risk Management; Kunreuther, H., Meyer, R.J., Michel-Kerjan, E.O., Eds.; University of Pennsylvania Press: Philadelphia, PA, 2019; Chapter 4, pp. 66-77.

23. Capstick, S.; Whitmarsh, L.; Poortinga, W.; Pidgeon, N.; Upham, P. International trends in public perceptions of climate change over the past quarter century. WIREs Clim. Chang. 2015, 6, 35-61, [CrossRef]

24. Kellens, W.; Terpstra, T.; Maeyer, P.D. Perception and communication of flood risks: A systematic review of empirical research. Risk Anal. 2013, 33, 24-49. [CrossRef]

25. Botzen, W.; Kunreuther, H.C.; Michel-Kerjan, E.O. Divergence between individual perceptions and objective indicators of tail risks: Evidence from floodplain residents in New York City. Judgm. Decis. Mak. 2015, 10, 365-385.

26. Royal, A.; Walls, M. Flood Risk Perceptions and Insurance Choice: Do Decisions in the Floodplain Reflect Overoptimism? Risk Anal. 2019, 39, 1088-1104. [CrossRef]

27. Mol, J.M.; Botzen, W.; Blasch, J.E.; de Moel, H. Insights into Flood Risk Misperceptions of Homeowners in the Dutch River Delta. Risk Anal. 2020, 40. [CrossRef]

28. Petrolia, D.R.; Landry, C.; Coble, K. Risk preferences, risk perceptions, and flood insurance. Land Econ. 2013, 89, 227-245. [CrossRef] 
29. Petrolia, D.R.; Hwang, J.; Landry, C.E.; Koble, K.H. Wind Insurance and Mitigation in the Coastal Zone. Land Econ. 2015, 96, 272-295. [CrossRef]

30. NOAA. Tropical Cyclone Climatology; National Oceananic and Atmosphetic Administration: Silver Spring, MD, USA, 2020.

31. Keim, B.D.; Muller, R.A.; Stone, G.W. Spatiotemporal patterns and return periods of tropical storm and hurricane strikes from Texas to Maine. J. Clim. 2007, 20, 3498-3509. [CrossRef]

32. Sandrik, A.; Landsea, C.W. Chronological Listing of Tropical Cyclones Affecting North Florida and Coastal Georgia 1565-1899. Technical Report; National Oceananic and Atmosphetic Administration: Silver Spring, MD, USA, 2003.

33. Needham, H. Matthew Makes The 'Protected Coast' the Most Dangerous Place of All; Technical Report; WXshift: Princeton, NJ, USA, 2016.

34. NOAA. Coastal Flood Exposure Mapper. Available online: https://coast.noaa.gov/floodexposure (accessed on 9 November 2020).

35. Amodeo, M.; Armal, S.; Arnell, M.; Bertan, E.; Brannock, J.; Brown, L.; Bubb, I.; Cantrell, G.; Chadwick, M.; Chadwick, S.; et al. The First National Flood Risk Assessment; Technical Report; The First Street Foundation: New York, NY, USA, 2020.

36. Bakkensen L.A.; Mendelsohn R.O. Risk and Adaptation: Evidence from Global Hurricane Damages and Fatalities. J. Assoc. Environ. Resour. Econ. 2016, 3, 555-587. [CrossRef]

37. Hirabayashi, Y.; Mahendran, R.; Koirala, S.; Konoshima, L.; Yamazaki, D.; Watanabe, S.; Kim, H.; Kanae, S. Global flood risk under climate change. Nat. Clim. Chang. 2013, 3, 816-821. [CrossRef]

38. Eckle, C.C.; Grossman, P.J. Sex differences and statistical stereotyping in attitudes toward financial risk. Evol. Hum. Behav. 2002, 23, 281-295. [CrossRef]

39. NFIP. October 2018 NFIP Flood Insurance Manual; Government Document; National Flood Insurance Program: Washington, DC, USA, 2018.

40. Hout, M. Getting the Most Out of the GSS Income Measures; GSS Methodological Report 101; UC Berkley Survey Research Center: Berkley, CA, USA, 2004.

41. von Neumann, J.; Morgenstern, O. Theory of Games and Economic Behavior; Princeton University Press: Princeton, NJ, USA, 1944.

42. Moscati, I. Retrospectives: How Economists Came to Accept Expected Utility Theory: The Case of Samuelson and Savage. J. Econ. Perspect. 2016, 30, 219-236. [CrossRef]

43. McFadden, D. Econometric Models of Probabilistic Choice. In Structural Analysis of Discrete Data with Econometric Applications; Manski, C.; McFadden, D., Eds.; MIT Press: Cambridge, MA, USA, 1981; pp. 198-272.

44. George, E.I.; McCulloch, R.E. Variable Selection Via Gibbs Sampling. J. Am. Stat. Assoc. 1993, 88, 881-889. [CrossRef]

45. Kuo, L.; Mallick, B. Variable Selection for Regression Models. Sankhya Indican J. Stat. Ser. B 1998, 60, 65-81.

46. Gelman, A.; Rubin, D.B. Inference from Iterative Simulations Using Multiple Sequences. Stat. Sci. 1992, 7, 457-472. [CrossRef]

47. O'Hara, R.; Sillanpaa, M. A Review of Bayesian Variable Selection Modths: What, How and Which. Bayesian Anal. 2009, 4, 85-118. [CrossRef]

48. Yin, H.; Chen, J.; Kunreuther, H.C.; Michel-Kerjan, E. Availability Heuristic and Gambler's Fallacy over Time in a Natural Disaster Insurance Choice Setting; Working Paper 2798371; Social Science Research Network: Rochester, NY, USA, 2016.

49. Bubeck, P.; Botzen, W.; Aerts, J. A Review of Risk Perceptions and Other Factors that Influence Flood Mitigation Behavior. Risk Anal. 2012, 32, 1481-1495. [CrossRef] [PubMed]

50. Dominitz, J.; Manski, C.F. Perceptions of Economic Insecurity: Evidence From the Survey of Economic Expectations. Public Opin. Q. 1997, 61, 261-287. [CrossRef]

51. de Bruin, W.B.; Fischbeck, P.S.; Stiber, N.A.; Fishhoff, B. What number is 'fifty-fifty'?: Redistributing Excessive 50\% Responses in Elicited Probabilities. Risk Anal. 2002, 22, 713-723. [CrossRef] [PubMed] 
52. Manski, C.F.; Molinari, F. Rounding Probabilistic Expectations in Surveys. J. Bus. Econ. Stat. 2010, 28, $219-231$. [CrossRef] [PubMed]

53. Bishop, R.C.; Boyle, K.J. Reliability and validity in nonmarket valuation. In A Primer on Nonmarket Valuation; Springer: Dordrecht, The Netherlands, 2017; pp. 463-497.

54. Haab, T.; Lewis, L.; Whitehead, J. State of the Art of Contingent Valuation. In Oxford Research Encyclopedia of Environmental Science; Oxford University Press: Oxford, UK, 2020.

55. Landry, C.E.; Jahan-Parvar, M.R. Flood insurance coverage in the coastal zone. J. Risk Insur. 2011, 78, 361-388. [CrossRef]

56. Kousky, C.; Lingle, B.; Shabman, L. The Pricing of Flood Insurance. J. Extrem. Events 2017, 4, 1750001. [CrossRef]

57. Ahmadiani, M.; Ferreira, S.; Landry, C.E. Flood Insurance and Risk Reduction: Market Penetration, Coverage, and Mitigation in Coastal North Carolina. South. Econ. J. 2019, 85, 1058-1082. [CrossRef]

Publisher's Note: MDPI stays neutral with regard to jurisdictional claims in published maps and institutional affiliations.

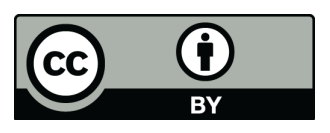

(C) 2020 by the authors. Licensee MDPI, Basel, Switzerland. This article is an open access article distributed under the terms and conditions of the Creative Commons Attribution (CC BY) license (http:/ / creativecommons.org/licenses/by/4.0/). 